\title{
lodine deficiency during pregnancy: a national cross-sectional survey in Latvia
}

\author{
Ilze Konrade ${ }^{1,2, *}$, leva Kalere ${ }^{1}$, leva Strele ${ }^{1}$, Marina Makrecka-Kuka ${ }^{1,3}$, Anna Jekabsone ${ }^{1}$, \\ Elina Tetere ${ }^{1}$, Vija Veisa ${ }^{1}$, Didzis Gavars ${ }^{4}$, Dace Rezeberga ${ }^{1}$, Valdis Pīrāgs ${ }^{5}$, \\ Aivars Lejnieks ${ }^{1,2}$ and Maija Dambrova ${ }^{1,3}$ \\ ${ }^{1}$ Riga Stradins University, Riga, Latvia: ${ }^{2}$ Department of Medicine, Riga East Clinical University Hospital, Hipokrata 2, \\ Riga LV1038, Latvia: ${ }^{3}$ Latvian Institute of Organic Synthesis, Riga, Latvia: ${ }^{4} \mathrm{E}$. Gulbis Laboratory, Riga, Latvia: \\ 5 University of Latvia, Riga, Latvia
}

Submitted 22 October 2014: Final revision received 23 December 2014: Accepted 29 January 2015: First published online 3 March 2015

\begin{abstract}
Objective: Low iodine intake during pregnancy may cause thyroid dysfunction, which results in inadequate fetal brain development. In the absence of a universal salt iodization programme, we conducted a nationwide survey of iodine deficiency in pregnant women in Latvia.

Design: A countrywide twenty-cluster survey, with at least twenty women per cluster. Participants completed a questionnaire on dietary habits concerning iodine intake ( $n$ 739). Thyroid function (thyroid-stimulating hormone, free thyroxine and thyroperoxidase antibodies) was measured ( $n$ 550). Urinary iodine was measured using the ammonium persulfate method ( $n$ 696).

Setting: The survey was performed in all regions of Latvia during the spring and autumn seasons in 2013.

Subjects: Pregnant women ( $n$ 829).

Results: The median creatinine ( $\mathrm{Cr}$ )-standardized urinary iodine concentration (UIC) was $80 \cdot 8$ (interquartile range (IQR) 46.1-130.6) $\mu \mathrm{g} / \mathrm{g}$ Cr or $69 \cdot 4$ (IQR 53.992.6) $\mu \mathrm{g} / \mathrm{l}$ during pregnancy, and $81 \%$ of pregnant women had UIC levels below the WHO recommended range of $150-250 \mu \mathrm{g} / \mathrm{g}$ Cr. The UIC was lowest during the first trimester of pregnancy, 56.0 (IQR 36.4-100.6) $\mu \mathrm{g} / \mathrm{g} \mathrm{Cr}$, reaching higher concentrations of 87.5 (IQR 46.4-141.7) $\mu \mathrm{g} / \mathrm{g} \mathrm{Cr}$ and 86.9 (IQR 53.8-140.6) $\mu \mathrm{g} / \mathrm{g} \mathrm{Cr}$ in the second and third trimesters, respectively. Women taking supplements containing $\geq 150 \mu \mathrm{g}$ iodine ( $6 \cdot 8 \%$ of respondents) had non-significantly higher UIC than did women without supplementation $(96.2 v .80 .3 \mu \mathrm{g} / \mathrm{g} \mathrm{Cr}$, respectively, $P=$ NS). Thyroperoxidase antibody concentration did not correlate significantly with UIC: Spearman's $\rho=-0 \cdot 012, P=0 \cdot 78$.

Conclusions: The median UIC indicates iodine deficiency in pregnant women in Latvia. Iodine supplementation $(150 \mu \mathrm{g}$ daily) and regular UIC monitoring should be suggested to overcome iodine deficiency and to reach the recommended levels without inducing autoimmune processes.
\end{abstract}

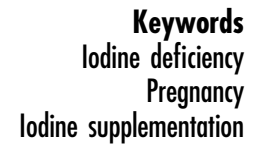

deficiency

lodine supplementation
It is well known that dietary iodine intake is required to produce thyroid hormones, but iodine-deficiency disorders still represent a global threat to individuals and societies $^{(1)}$. Since 1922, when Switzerland was the first country to establish a national iodine fortification programme, considerable progress worldwide has been achieved; the number of iodine-sufficient countries has increased to 111 and only thirty countries remain mildly or moderately iodine-deficient ${ }^{(2)}$. Despite this overall progress, recent data suggest that most pregnant women appear not to be protected against iodine deficiency, even in areas with adequate iodine intake ${ }^{(3,4)}$. Therefore, the development of effective prevention and monitoring programmes for iodine-deficiency disorders would be required in all countries because pregnant women represent the most susceptible and vulnerable group and because mild iodine deficiency may impair neuropsychological and motor development in children, preventing them from reaching their full intellectual potential ${ }^{(5,6)}$.

A recent meta-analysis has shown that at 5 years of age, children's intelligence quotient is 7.4 points lower due to iodine deficiency during pregnancy ${ }^{(7)}$. Econometric models have established that this result greatly impacts not only individuals but also society as a whole, because 
a 1-point decrease in intelligence quotient has been associated with a persistent $0 \cdot 11 \%$ annual decrease in per capita gross domestic product, which is connected with a recession in the economy and tends to translate into decreased productivity ${ }^{(8)}$. These substantial consequences result from the fact that even mild iodine deficiency disrupts the metabolism of thyroid hormones, which are a critical endocrine regulator of early brain development ${ }^{(9)}$. Thyroid hormones act specifically by regulating the genes that underlie major neurodevelopmental events, including neurogenesis, axon and dendrite formation, neuronal migration, synaptogenesis and myelination ${ }^{(10-14)}$. Thyroid hormones are also involved in the regulation of BMR and macronutrient metabolism ${ }^{(15)}$.

During pregnancy, iodine requirements increase substantially because of increased thyroid hormone synthesis and demand. Due to the trend of insufficient iodine intake in pregnancy, the WHO has increased the daily iodine intake recommendation for pregnancy to $250 \mu \mathrm{g}^{(1)}$. In most countries, this intake is not provided by food sources, even more so because of suggestions by the US Food and Drug Administration and Environmental Protection Agency that pregnant women and nursing mothers lower their intakes of fish and shellfish that contain low levels of mercury and avoid products that have high levels ${ }^{(16)}$. In addition, in countries such as Latvia, where the consumption of iodized salt is voluntary, the household coverage of iodized salt varies widely (i.e. lower dietary salt intake and decreased proportion of foods fortified with iodine).

Recently, a meta-analysis from the UK observed that iodine supplementation improves maternal thyroid indices and parameters of cognitive function, even in marginal iodine-deficient areas ${ }^{(17)}$. Nevertheless, in clinical practice, iodine supplementation is associated with concerns that sharp increases in iodine intake, even in marginally iodine-deficient populations, may increase the prevalence of thyroperoxidase antibodies (TPO-Ab) ${ }^{(18)}$. Therefore, the aim of the present nationally representative study was to assess the iodine status among pregnant women in Latvia and study the possible associations between TPO-Ab, thyroid-stimulating hormone (TSH) and free throxine $\left(\mathrm{fT}_{4}\right)$ and iodine supplementation.

\section{Materials and methods}

To obtain results that could be extrapolated to all pregnant women in Latvia, a twenty-cluster survey was performed in all regions of Latvia during the spring and autumn seasons in 2013, with at least twenty women per cluster. Sample size calculation was based on an estimated $70.4 \%$ prevalence of urinary iodine concentration (UIC) $<150 \mu \mathrm{g} / \mathrm{l}$, a $95 \%$ confidence interval, a design effect of 2 and an absolute precision $5 \%$, resulting in a total sample size of 642 women. This prevalence figure was based on a population survey among Latvian schoolchildren ${ }^{(19)}$. All included women were Caucasian. After receiving a detailed explanation from the study midwife, the study participants independently completed a questionnaire concerning the use of iodine supplements and the consumption of seafood, dairy products and iodized household salt, as well as smoking history, previous thyroid diseases and parity. From each participant a single blood sample and a portion of urine were collected for laboratory tests.

\section{Laboratory measurements}

An assay to detect urinary iodine using ammonium persulfate was adapted from methods described previously ${ }^{(20)}$. Absorption measurements were obtained at $405 \mathrm{~nm}$ after 30 min incubation at room temperature using a $\mu$ Quant ${ }^{\mathrm{TM}}$ Microplate Spectrophotometer (BioTek Instruments, Winooski, VT, USA). The urinary creatinine concentration was measured using the Jaffe method ${ }^{(21)}$ with the intention that iodine concentration adjusted for creatinine concentration (iodine/Cr) could be calculated. Creatininestandardized UIC is a more reliable method of iodine excretion than random spot UIC measurement since there is a great day-to-day variability in water intake ${ }^{(22)}$. Blood samples were sent to the E. Gulbis Laboratory (Riga, Latvia), which operates according to EN ISO 15189:2008 standard. $\mathrm{TSH}_{1} \mathrm{fT}_{4}$ and $\mathrm{TPO}-\mathrm{Ab}$ were measured by chemiluminescence immunoassay (Siemens, Malvern, PA, USA) performed on an Advia Centaur XP (Siemens) analyser. We used the reference range recommended by the American Thyroid Association ${ }^{(23)}$ for serum TSH (first trimester, $0 \cdot 1-2.5 \mathrm{mIU} / 1$; second trimester, $0.2-3.0 \mathrm{mIU} / \mathrm{l}$; third trimester, 0.3-3.0 mIU/l) and TPO-Ab (0-64 IU/ml). Because the issue of TPO-Ab positivity in relation to iodine supplementation is clinically relevant, only pregnant women without known pre-existing thyroid disease were selected for the statistical analysis. Out of 665 women without prior thyroid disease, TPO-Ab was measured in 496 (number of women tested in the first, second and third trimesters were 122, 182 and 192, respectively).

\section{Statistical analyses}

The results are expressed as medians with interquartile range (IQR) and as percentage of participants in the study. The Mann-Whitney $U$ test or Kruskal-Wallis test was used to compare UIC between two or more subgroups, respectively. Differences between prevalence estimates were tested using the $\chi^{2}$ test or Fisher's exact test, as appropriate. Spearman's rank correlation analysis was performed. $P$ values below 0.05 were considered statistically significant. Multivariate linear regression was used to analyse the factors associated with logarithmically transformed creatinine-standardized UIC, and multivariate logistic regression was used to analyse the factors associated with elevated TPO-Ab (>60 IU/ml). Only women with complete records were included in multivariate regression analyses. The data were analysed using the IBM SPSS $19 \cdot 0$ statistical software package and the Confidence Interval Analysis software. 


\section{Results}

Of the 829 pregnant women enrolled in the current study, 739 women completed the study questionnaire (Table 1). Of the 162 women in the first trimester of pregnancy at the time of evaluation, $50 \cdot 3 \%$ ( $n$ 81) reported regular use of any dietary supplements irrespective of iodine content. The percentage of women using supplements was $63.6 \%$ ( $n$ 178) in the second trimester and $65.5 \%$ ( $n$ 190) in the third trimester; both values were significantly greater than those of women in the first trimester who used supplements $(P=0.006$ and $P=0.002$, respectively). Only $3.1 \%$ ( $n$ 5) of women used supplements containing $\geq 150 \mu \mathrm{g}$ iodine in the first trimester. The percentage of women using these supplements was also significantly greater in the second trimester ( $P=0.008)$, reaching $10 \cdot 0 \%$ ( $n$ 28), but the percentage was not significantly greater in the third trimester $(5.9 \%(n$ 17)) compared with the first trimester $(P=0 \cdot 193)$.

The UIC was measured in 696 pregnant women (Fig. 1). The median UIC among pregnant women was $80 \cdot 8$ (IQR 46.1-130.6) $\mu \mathrm{g} / \mathrm{g} \mathrm{Cr}(69 \cdot 4$ (IQR 53.9-92.6) $\mu \mathrm{g} / \mathrm{l}$ ); the $0.5 \%$ percentile was $3.0 \mu \mathrm{g} / \mathrm{g} \mathrm{Cr}$ and the $99.5 \%$ percentile was $621.4 \mu \mathrm{g} / \mathrm{g}$ Cr. Of these women, $81 \%$ had UIC measurements below $150 \mu \mathrm{g} / \mathrm{g} \mathrm{Cr}, 62 \%$ had UIC below $100 \mu \mathrm{g} / \mathrm{g}$ Cr and $28 \%$ had UIC below $50 \mu \mathrm{g} / \mathrm{g}$ Cr. Only $7 \%$ of the pregnant women exceeded a UIC of $249.9 \mu \mathrm{g} / \mathrm{g} \mathrm{Cr}$ and $1 \%$ ( $n$ 7) had UIC above $500 \mu \mathrm{g} / \mathrm{g}$ Cr. The median standardized UIC in the first trimester was significantly lower than that in the second and third trimesters $(P<0 \cdot 001$ for both; Fig. 2(a) and (b)). A significant negative correlation between the gestational week and $\mathrm{fT}_{4}$ concentration was observed (Spearman's $\rho=-0.367, \quad P<0.001$; data not shown). The median $\mathrm{fT}_{4}$ concentration was $14.4 \mathrm{pmol} / 1$ in the first trimester, $13.1 \mathrm{pmol} / 1$ in the second trimester and $12.5 \mathrm{pmol} / \mathrm{l}$ in the third trimester $(P<0.001)$. Hypothyroxinaemia (as defined by $\mathrm{fT}_{4}$ concentration below $10.3 \mathrm{pmol} / \mathrm{l}$ ) was not detected in the first trimester but reached the prevalence of $2.5 \%$ in the second trimester and $10.7 \%$ in the third trimester $(P<0.001)$. In the setting of mild maternal iodine deficiency, hypothyroxinaemia was not associated with UIC and TPO-Ab.

As shown in Table 2, the median UIC was $80 \cdot 3$ (45.8127.9) $\mu \mathrm{g} / \mathrm{g} \mathrm{Cr}$ in the group of women who did not use iodine-containing supplements or used supplements with an iodine content of $<100 \mu \mathrm{g}$. A non-significantly higher median UIC of $86 \cdot 2 \mu \mathrm{g} / \mathrm{g}$ Cr was detected in women using supplements with 100-149 $\mu \mathrm{g}$ iodine and $96 \cdot 2 \mu \mathrm{g} / \mathrm{g}$ Cr with $\geq 150 \mu \mathrm{g}$ iodine $(P=0 \cdot 471)$. Women who regularly used iodized salt had a non-significantly higher median UIC than did those who used regular salt, at 86.2 and $79.9 \mu \mathrm{g} / \mathrm{g}$ $\mathrm{Cr}$, respectively $(P=0 \cdot 234)$. Women who reported only rarely consuming milk products had a median UIC of $65.2 \mu \mathrm{g} / \mathrm{g} \mathrm{Cr}$, which was significantly lower than that in the group of women consuming approximately three servings of milk products daily $(87.6 \mu \mathrm{g} / \mathrm{g} \mathrm{Cr} ; P=0.002)$ and the
Table 1 Characteristics of the study population: nationally representative sample of pregnant women ( $n$ 739), Latvia, 2013

\begin{tabular}{|c|c|c|}
\hline & $\%$ & $n$ \\
\hline \multicolumn{3}{|l|}{ Trimester } \\
\hline First & 21.9 & 162 \\
\hline Second & 38.2 & 282 \\
\hline Third & 39.9 & 295 \\
\hline \multicolumn{3}{|l|}{ First pregnancy } \\
\hline Yes & $45 \cdot 3$ & 335 \\
\hline No & 54.7 & 404 \\
\hline \multicolumn{3}{|l|}{ Season } \\
\hline Spring & 53.9 & 398 \\
\hline Autumn & $46 \cdot 1$ & 341 \\
\hline \multicolumn{3}{|c|}{ Use of supplements containing iodine } \\
\hline$\geq 150 \mu \mathrm{g}$ & $6 \cdot 8$ & 50 \\
\hline $100-149 \mu \mathrm{g}$ & $10 \cdot 4$ & 77 \\
\hline$<100 \mu \mathrm{g}$ or no use & 81.7 & 604 \\
\hline Not known & $1 \cdot 1$ & 8 \\
\hline \multicolumn{3}{|l|}{ Use of iodized salt } \\
\hline Always & 8.9 & 66 \\
\hline Sometimes & $36 \cdot 1$ & 267 \\
\hline No & $54 \cdot 8$ & 405 \\
\hline Not known & 0.1 & 1 \\
\hline \multicolumn{3}{|c|}{ Consumption of milk and dairy products } \\
\hline $2-4$ servings/d & 37.5 & 277 \\
\hline 1 serving/d & $50 \cdot 3$ & 372 \\
\hline Rarely/less than once daily & 11.0 & 81 \\
\hline Not known & $1 \cdot 2$ & 9 \\
\hline \multicolumn{3}{|l|}{ Consumption of seafood } \\
\hline $2-3$ times/week & $5 \cdot 0$ & 37 \\
\hline Once weekly & $45 \cdot 9$ & 339 \\
\hline Less than once weekly & $47 \cdot 9$ & 354 \\
\hline Not known & $1 \cdot 2$ & 9 \\
\hline \multicolumn{3}{|l|}{ Smoking } \\
\hline Yes & $7 \cdot 2$ & 53 \\
\hline Stopped during pregnancy & $35 \cdot 2$ & 260 \\
\hline No & $56 \cdot 2$ & 415 \\
\hline Not known & 1.5 & 11 \\
\hline \multicolumn{3}{|l|}{ History of thyroid disease } \\
\hline Yes & $9 \cdot 6$ & 71 \\
\hline No & $90 \cdot 0$ & 665 \\
\hline Not known & 0.4 & 3 \\
\hline \multicolumn{3}{|l|}{ TPO-Ab > $60 \mathrm{IU} / \mathrm{ml}$} \\
\hline Yes & $10 \cdot 7$ & 79 \\
\hline No & $63 \cdot 6$ & 470 \\
\hline Not known & $25 \cdot 7$ & 190 \\
\hline \multicolumn{3}{|l|}{ Elevated trimester-specific TSH† } \\
\hline Yes & 3.8 & 28 \\
\hline No & $70 \cdot 6$ & 522 \\
\hline Not known & $25 \cdot 6$ & 189 \\
\hline \multicolumn{3}{|l|}{ Decreased $\mathrm{fT}_{4}$} \\
\hline Yes & $3 \cdot 8$ & 28 \\
\hline No & $70 \cdot 6$ & 522 \\
\hline Not known & $25 \cdot 6$ & 189 \\
\hline
\end{tabular}

TPO-Ab, thyroperoxidase antibodies; TSH, thyroid-stimulating hormone; $\mathrm{fT}_{4}$, free thyroxine.

†According to the guidelines of the American Thyroid Association: first trimester, $>2.5 \mathrm{mlU} / \mathrm{l}$; second trimester, $>3.0 \mathrm{mlU} / \mathrm{l}$; third trimester, $>3.0 \mathrm{mlU} / \mathrm{l}$.

women consuming one portion of milk products daily $(80 \cdot 1 \mu \mathrm{g} / \mathrm{g} \mathrm{Cr} ; P=0 \cdot 047)$. The difference between the latter two groups was non-significant $(P=0 \cdot 076)$.

Multivariate linear regression analysis was performed to assess the demographic and dietary factors associated with creatinine-standardized UIC in the present study. As shown in Table 3, the women's age, gestational age, milk consumption (at least one serving daily) and seafood 


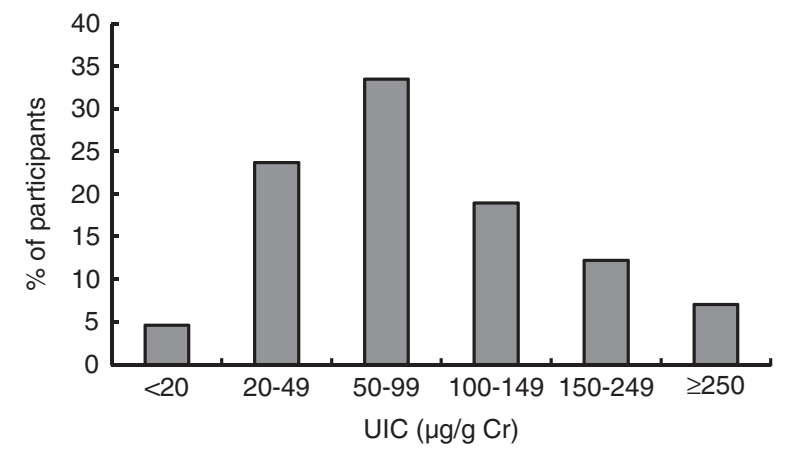

Fig. 1 Frequency distribution of iodine excretion among a nationally representative sample of pregnant women ( $n$ 696), Latvia, 2013 (UIC, urinary iodine concentration; Cr, creatinine)
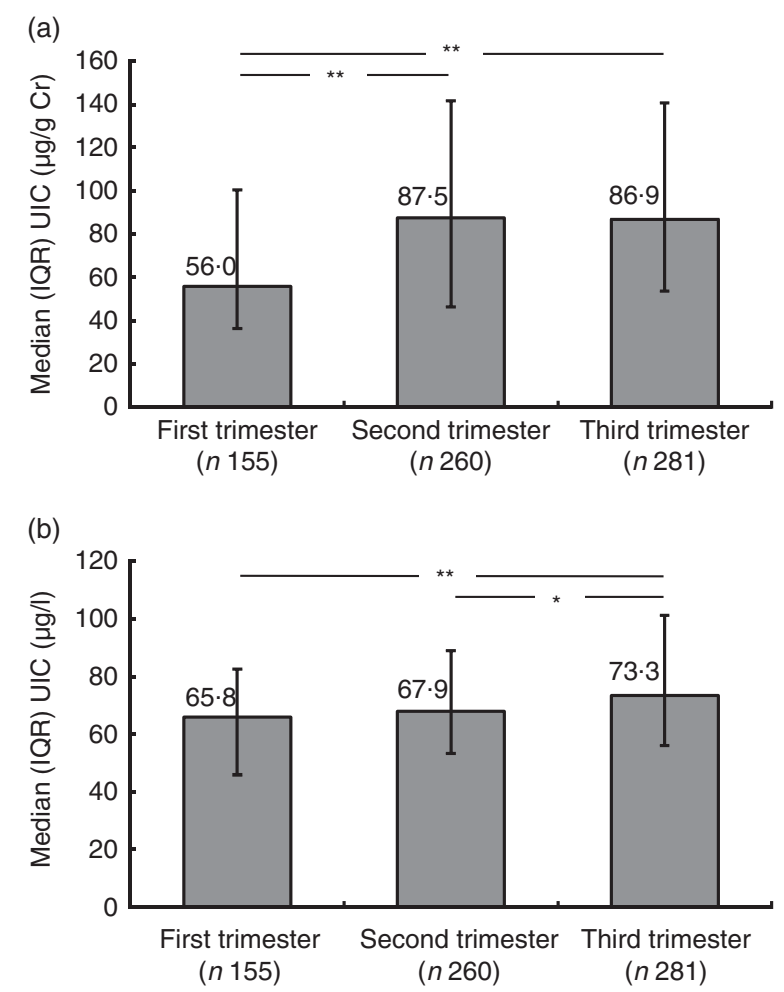

Fig. 2 Median iodine excretion during pregnancy trimesters among a nationally representative sample of pregnant women ( $n$ 696), Latvia, 2013: (a) UIC ( $\mu \mathrm{g} / \mathrm{g}$ Cr); (b) UIC ( $\mu \mathrm{g} / \mathrm{l})$. Values are medians with interquartile ranges represented by vertical lines; horizontal lines linking bars indicate statistically significant $\left({ }^{\star} P<0.05 ;{ }^{* \star} P<0.001\right)$ differences between the groups (UIC, urinary iodine concentration; $\mathrm{Cr}$, creatinine; IQR, interquartile range)

consumption (once weekly) were independently associated with a higher UIC, but parity was associated with a lower UIC.

Because the issue of TPO-Ab positivity in relation to iodine supplementation is clinically relevant, only pregnant women without known pre-existing thyroid disease were selected for the statistical analysis ( $n$ 496). The prevalence of TPO-Ab concentration above $60 \mathrm{U} / \mathrm{ml}$ in spring was $17 \cdot 3 \%$, which was significantly higher than that in autumn, $8.9 \%(P=0.005$; Table 4$)$. The prevalence of TPO-Ab concentration above the reference range in the group of women with TSH concentration within the trimester-specific range was $12.5 \%$, but it reached a higher prevalence of $21.7 \%$ in women with an elevated trimesterspecific TSH concentration, although the difference was not statistically significant $(P=0 \cdot 201)$. No association between higher prevalence of elevated TPO-Ab concentration and iodine content in supplements was detected in our study ( $P$ for trend $=0.565$ ). Multivariate logistic regression analysis indicated that the odds of having an elevated TPO-Ab concentration were almost two times greater in spring than in autumn $(\mathrm{OR}=1.97$; $95 \%$ CI 1.09 , 3.54) and nearly three times lower in women consuming one serving of dairy products daily than in women rarely consuming dairy products (OR $=0.38 ; 95 \% \mathrm{CI} 0 \cdot 17,0 \cdot 85)$. The odds of having a TPO-Ab concentration $>60 \mathrm{U} / \mathrm{ml}$ were not increased by using supplements containing iodine, consuming iodized salt or fish, age, gestational age, parity or smoking habits.

\section{Discussion}

A previous cross-sectional school-based survey in Latvia showed that the median inter-seasonal creatininestandardized UIC in schoolchildren was $107 \cdot 3$ (IQR 69.1-161.7) $\mu \mathrm{g} / \mathrm{g} \mathrm{Cr}^{(19)}$. Despite the fact that the overall median UIC in schoolchildren remained within the lownormal range, a large percentage of the Latvian population had suboptimal iodine intake and were found to be iodine-deficient. This result occurs for example in pregnancy, when maternal needs for thyroid hormone increase due to the transfer of iodine and thyroid hormone to the fetus and the increase in maternal renal iodine clearance $^{(24)}$. Without a mandatory salt fortification programme or the iodization of cattle food (there are no nationally representative data on iodine content in milk available) and with a decreasing proportion of food being fortified with iodine, an inevitable outcome is iodine deficiency. This outcome is also illustrated by the results of the present study of pregnant women in Latvia, where the median UIC of $80.8 \mu \mathrm{g} / \mathrm{g} \mathrm{Cr}$ indicates insufficient iodine intake according to WHO criteria ${ }^{(1)}$.

Several recent studies have suggested suboptimal iodine status in pregnant women living in areas with only partial coverage of iodized salt, such as Italy, the UK and the $\mathrm{USA}^{(25-27)}$. In a limited number of studies, long-term iodization before pregnancy showed more favourable effects on thyroid function than did short-term iodization and the early initiation of iodine supplements was more effective than beginning treatment in late pregnancy ${ }^{(28)}$. The present study also indicates that the median IUC was significantly higher in the second and third trimesters, which could be attributed to the intake of iodinecontaining supplements. However, the intake of iodine 
Table 2 UIC ( $\mu \mathrm{g} / \mathrm{g} \mathrm{Cr}$ ) according to the participants' characteristics and dietary habits; nationally representative sample of pregnant women (n 696), Latvia, 2013

\begin{tabular}{|c|c|c|c|c|c|c|}
\hline & $n$ & Median & IQR & $P$ & UIC $<150 \mu \mathrm{g} / \mathrm{g}$ Cr (\%) & $P$ for trend $\left(x^{2}\right.$ test $)$ \\
\hline \multicolumn{7}{|c|}{ Use of supplements containing iodine } \\
\hline$\geq 150 \mu \mathrm{g}$ & 48 & $96 \cdot 2$ & $51 \cdot 9-140 \cdot 3$ & & $81 \cdot 2$ & \\
\hline $100-149 \mu \mathrm{g}$ & 70 & $86 \cdot 2$ & $46 \cdot 6-156 \cdot 9$ & & 71.4 & \\
\hline$<100 \mu \mathrm{g}$ or no use & 570 & $80 \cdot 3$ & $45 \cdot 8-127.9$ & $0.471^{*}$ & 81.9 & 0.295 \\
\hline \multicolumn{7}{|l|}{ Use of iodized salt } \\
\hline Always & 60 & $86 \cdot 2$ & $50 \cdot 9-153 \cdot 6$ & & $75 \cdot 0$ & \\
\hline Sometimes & 254 & $82 \cdot 8$ & $48 \cdot 7-133 \cdot 2$ & & $80 \cdot 3$ & \\
\hline No & 381 & 79.9 & $43 \cdot 6-126 \cdot 3$ & $0.465^{\star}$ & 81.9 & 0.243 \\
\hline \multicolumn{7}{|c|}{ Consumption of milk and dairy products } \\
\hline $2-4$ servings/d & 263 & 87.6 & $50 \cdot 8-143.9$ & & 77.9 & \\
\hline 1 serving/d & 347 & $80 \cdot 1$ & $44 \cdot 6-134.6$ & & $81 \cdot 3$ & \\
\hline Rarely/less than once daily & 77 & $65 \cdot 2$ & $40 \cdot 0-101 \cdot 7$ & $0.007^{\star}$ & 88.3 & 0.048 \\
\hline \multicolumn{7}{|l|}{ Consumption of seafood } \\
\hline 2-3 times/week & 36 & 83.8 & $42 \cdot 6-173.7$ & & 69.4 & \\
\hline Once weekly & 319 & $86 \cdot 8$ & $47 \cdot 7-141 \cdot 0$ & & $79 \cdot 0$ & \\
\hline Less than once weekly & 332 & $76 \cdot 9$ & $45 \cdot 0-115 \cdot 1$ & $0.061^{*}$ & 83.7 & 0.023 \\
\hline \multicolumn{7}{|l|}{ Smoking } \\
\hline Yes & 52 & $75 \cdot 6$ & $41 \cdot 7-115 \cdot 1$ & & 88.5 & \\
\hline Stopped during pregnancy & 242 & $82 \cdot 2$ & $47 \cdot 9-134.8$ & & 79.8 & \\
\hline No & 391 & $82 \cdot 1$ & $46 \cdot 0-132 \cdot 5$ & $0.285^{\star}$ & $80 \cdot 6$ & 0.429 \\
\hline \multicolumn{7}{|l|}{ Season } \\
\hline Spring & 370 & $82 \cdot 9$ & $47 \cdot 4-132 \cdot 6$ & & 81.4 & \\
\hline Autumn & 326 & 79.7 & $43 \cdot 9-131 \cdot 2$ & $0.608 \dagger$ & $80 \cdot 1$ & 0.667 \\
\hline \multicolumn{7}{|l|}{ First pregnancy } \\
\hline Yes & 318 & 79.9 & $47.4-131.5$ & & 80.5 & \\
\hline No & 378 & $82 \cdot 8$ & $45 \cdot 5-132 \cdot 6$ & $0.715 \dagger$ & 81.0 & 0.881 \\
\hline \multicolumn{7}{|l|}{ Trimester } \\
\hline First & 155 & $56 \cdot 0$ & $36 \cdot 4-100 \cdot 6$ & & 88.4 & \\
\hline Second & 260 & $87 \cdot 5$ & $46 \cdot 4-141 \cdot 7$ & & 78.5 & \\
\hline Third & 281 & $86 \cdot 9$ & $53 \cdot 8-140 \cdot 6$ & $<0.001^{\star}$ & 78.6 & 0.027 \\
\hline \multicolumn{7}{|l|}{ Age } \\
\hline$<28$ years & 346 & 79.6 & $45 \cdot 1-127 \cdot 9$ & & 81.5 & \\
\hline$\geq 28$ years & 350 & 83.2 & $46 \cdot 3-135 \cdot 9$ & $0.345 \dagger$ & $80 \cdot 0$ & 0.615 \\
\hline
\end{tabular}

UIC, urinary iodine concentration; $\mathrm{Cr}$, creatinine; IQR, interquartile range.

${ }^{*} P$ value from Kruskal-Wallis test.

†P value from Mann-Whitney $U$ test.

Table 3 The association between dietary factors and participants' characteristics and logarithmically transformed UIC ( $\mu \mathrm{g} / \mathrm{g}$ Cr) in multiple linear regression analysis; nationally representative sample of pregnant women ( $n$ 683), Latvia, 2013

\begin{tabular}{|c|c|c|c|c|}
\hline & $\beta$ & SE & $95 \% \mathrm{Cl}$ & $P$ \\
\hline Age (years) & 0.007 & 0.003 & $0.002,0.013$ & 0.011 \\
\hline Gestational age (weeks) & 0.006 & 0.001 & $0.003,0.008$ & $<0.001$ \\
\hline Parity (number of previous pregnancies) & -0.034 & 0.016 & $-0.066,-0.002$ & 0.038 \\
\hline \multicolumn{5}{|l|}{ Use of iodine-containing supplements } \\
\hline$\geq 150 \mu \mathrm{g}$ & 0.052 & 0.052 & $-0.050,0.155$ & 0.319 \\
\hline $100-149 \mu \mathrm{g}$ & 0.033 & 0.044 & $-0.054,0.119$ & 0.459 \\
\hline$<100 \mu \mathrm{g}$ or no use (reference) & 0 & - & - & - \\
\hline \multicolumn{5}{|l|}{ Use of iodized salt } \\
\hline Always & 0.008 & 0.050 & $-0.091,0.107$ & 0.871 \\
\hline Sometimes & -0.012 & 0.030 & $-0.070,0.046$ & 0.690 \\
\hline No (reference) & 0 & - & - & - \\
\hline \multicolumn{5}{|l|}{ Consumption of milk and dairy products } \\
\hline $2-4$ servings/d & $0 \cdot 115$ & 0.046 & $0.024,0.205$ & 0.013 \\
\hline 1 serving/d & 0.087 & 0.044 & $0.000,0.175$ & 0.049 \\
\hline Rarely/less than once daily (reference) & 0 & - & - & - \\
\hline \multicolumn{5}{|l|}{ Consumption of seafood } \\
\hline 2-3 times/week & 0.092 & 0.063 & $-0.032,0.216$ & 0.145 \\
\hline Once weekly & 0.064 & 0.028 & $0.009,0.120$ & 0.024 \\
\hline Less than once weekly (reference) & 0 & - & - & - \\
\hline \multicolumn{5}{|l|}{ Smoking } \\
\hline Yes & 0.006 & 0.053 & $-0.099,0.111$ & 0.915 \\
\hline Stopped during pregnancy & 0.031 & 0.029 & $-0.025,0.088$ & 0.277 \\
\hline No (reference) & 0 & - & - & - \\
\hline \multicolumn{5}{|l|}{ Season } \\
\hline Spring $v$. autumn & 0.002 & 0.027 & $-0.050,0.055$ & 0.930 \\
\hline
\end{tabular}

UIC, urinary iodine concentration; $\mathrm{Cr}$, creatinine. 
Table 4 The association between patients' characteristics and dietary factors and the prevalence of elevated TPO-Ab (>60 U/ml) during pregnancy in multiple logistic regression analysis; nationally representative sample of pregnant women ( $n$ 496), Latvia, 2013

\begin{tabular}{|c|c|c|c|c|c|}
\hline & $\begin{array}{l}\text { Number of participants } \\
\text { in subgroup }\end{array}$ & $\begin{array}{c}\text { Prevalence of elevated } \\
\text { TPO-Ab (\%) }\end{array}$ & OR & $95 \% \mathrm{Cl}$ & $P$ \\
\hline Age (years) & & & 1.04 & $0.98,1.11$ & 0.194 \\
\hline Gestational age (weeks) & & & 0.98 & $0.95,1.01$ & 0.198 \\
\hline Parity (number of previous pregnancies) & & & 0.88 & $0.62,1.25$ & 0.473 \\
\hline \multicolumn{6}{|l|}{ Use of supplements containing iodine } \\
\hline$\geq 150 \mu \mathrm{g}$ & 39 & $12 \cdot 8$ & 1.17 & $0.42,3.30$ & 0.764 \\
\hline $100-149 \mu \mathrm{g}$ & 56 & 8.9 & 0.80 & $0.29,2.20$ & 0.665 \\
\hline$<100 \mu \mathrm{g}$ or no use (reference) & 393 & 13.7 & 1.00 & - & - \\
\hline \multicolumn{6}{|l|}{ Use of iodized salt } \\
\hline Always & 42 & $7 \cdot 1$ & 0.66 & $0.18,2.42$ & 0.535 \\
\hline Sometimes & 174 & 14.4 & 1.04 & $0.56,1.95$ & 0.895 \\
\hline No (reference) & 280 & $12 \cdot 9$ & 1.00 & - & - \\
\hline \multicolumn{6}{|l|}{ Consumption of milk and dairy products } \\
\hline $2-4$ servings/d & 181 & $13 \cdot 3$ & 0.52 & $0.22,1 \cdot 20$ & 0.124 \\
\hline 1 serving/d & 250 & $10 \cdot 8$ & 0.38 & $0.17,0.85$ & 0.019 \\
\hline Rarely/less than once daily (reference) & 56 & 23.2 & 1.00 & - & - \\
\hline \multicolumn{6}{|l|}{ Consumption of seafood } \\
\hline At least once weekly & 244 & $12 \cdot 3$ & 0.90 & $0.49,1.65$ & 0.735 \\
\hline Less than once weekly (reference) & 243 & $14 \cdot 0$ & 1.00 & - & - \\
\hline \multicolumn{6}{|l|}{ Smoking } \\
\hline Yes & 34 & $20 \cdot 6$ & 1.73 & $0.63,4.74$ & 0.291 \\
\hline Stopped during pregnancy & 168 & $11 \cdot 3$ & 0.77 & $0.40,1.48$ & 0.425 \\
\hline No (reference) & 285 & 13.3 & 1.00 & - & - \\
\hline \multicolumn{6}{|l|}{ Season } \\
\hline Spring & 237 & $17 \cdot 3$ & 1.97 & $1.09,3.54$ & 0.024 \\
\hline Autumn (reference) & 259 & 8.9 & 1.00 & - & - \\
\hline \multicolumn{6}{|l|}{ Elevated trimester-specific TSH } \\
\hline Yes & 23 & $21 \cdot 7$ & 3.00 & $0.97,9.35$ & 0.058 \\
\hline No (reference) & 473 & 12.5 & 1.00 & - & - \\
\hline $\mathrm{fT}_{4}(\mathrm{pmol} / \mathrm{l})$ & & & 0.90 & $0.77,1.04$ & 0.158 \\
\hline UIC $(\mu \mathrm{g} / \mathrm{g}$ Cr $)$ & & & 1.00 & $0.99,1.00$ & 0.204 \\
\hline
\end{tabular}

TPO-Ab, thyroperoxidase antibodies; $\mathrm{TSH}$, thyroid-stimulating hormone; $\mathrm{fT}_{4}$, free thyroxine; UIC, urinary iodine concentration; $\mathrm{Cr}$, creatinine.

supplements containing $150 \mu \mathrm{g}$ iodine, as recommended by the American Thyroid Association ${ }^{(29)}$, did not explain that association and also did not appear to be more effective in reducing the iodine deficiency during pregnancy. This might be attributed to the fact that in our study there was an insufficient number of women taking supplements containing $\geq 150 \mu \mathrm{g}$ iodine to find the difference between subgroups statistically significant. Our data support the notion that the iodine deficiency was most likely already present before pregnancy.

$\mathrm{We}^{(19)}$, along with others ${ }^{(30,31)}$, have reported seasonal UIC fluctuations in mild iodine-deficient regions of Europe. The data from the Latvian Neonatal TSH Registry also confirmed the seasonal differences in TSH levels in infants ${ }^{(19)}$. However, in the present study, we did not find significant seasonal differences in IUC in pregnant women. This finding might result from the guidelines of the International Council for the Control of Iodine Deficiency Disorders and WHO suggesting that pregnant women intake approximately $40-50 \%$ of iodine as dietary supplements, which masks the effect of seasonal pattern-dependent food sources, such as milk and milk products ${ }^{(32)}$.

Surprisingly, contrary to the finding of no seasonality effect in the UIC values, our study reports that the prevalence of elevated TPO-Ab concentration was approximately two times higher in spring than in autumn. This finding is the first time that such an observation has been reported in pregnant women. Some type of seasonality effect has been observed in both the onset of type 1 diabetes mellitus and subclinical $\beta$-cell autoimmunity ${ }^{(33)}$, which is similar to the trends of seasonal respiratory tract infections (as the initial trigger). We have no information regarding previous history nor did we test for infection in our study population; therefore, the idea that infection is a contributing factor to TPO-Ab production remains speculative. In addition, a role for lower vitamin $\mathrm{D}$ levels is discussed in thyroid autoimmunity, but recent studies are inconsistent in this aspect ${ }^{(34,35)}$.

In the present study, we did not observe any association between UIC and elevated TPO-Ab values. When more than $80 \%$ of the pregnant women have UIC lower than $150 \mu \mathrm{g} / \mathrm{g} \mathrm{Cr}$, iodine supplementation is not expected to trigger thyroid autoimmunity, a result that has been noted in populations with UIC that were approximately three times greater ${ }^{(36)}$. In countries such as Latvia, excessive iodine intake is unlikely, even when regularly consuming iodized salt at the WHO recommended amount of $5 \mathrm{~g} / \mathrm{d}^{(37)}$ and seafood once weekly during the pregnancy. Thus, in pregnant women natural dietary sources of iodine nutrition are less important. 
In previous studies with randomized $\mathrm{TPO}-\mathrm{Ab}^{+}$women who received placebo or iodine treatment, the results were not statistically significantly different in terms of the rate of postpartum thyroid dysfunction ${ }^{(17)}$; therefore, the addition of $150 \mu \mathrm{g}$ iodine daily does not pose a risk in a marginally iodine-deficient population such as Latvia. Taking into account the results of the present study, national recommendations for iodine status optimization should be targeted at fetal neurocognitive prophylaxis, initiated by daily supplementation with $100 \mu \mathrm{g}$ iodine and folic acid for women without known thyroid disease in the preconception period. At the first prenatal visit supplements containing $150 \mu \mathrm{g}$ of iodine should be recommended. Because iodine may increase thyroid autoimmunity in man and this can occur at iodine amounts that are necessary to prevent iodine deficiency ${ }^{(38)}$, a universal autoimmune thyroid disease screening in the first trimester of pregnancy ${ }^{(39)}$ should be also recommended.

In our study, we report UIC in $\mu \mathrm{g} / \mathrm{g} \mathrm{Cr}$ units. It is well known that during normal pregnancy, the glomerular filtration rate and renal plasma flow in women increase by 40-65\% and 50-85\%, respectively, and that tubular function and the processing of water and electrolytes are altered $^{(40)}$; in addition, changes in fluid intake may influence UIC results ${ }^{(41)}$. Therefore, UIC standardization to urine creatinine minimizes the variation due to dilution and urine volume because both vary depending on different factors of pregnancy. In our opinion, it would be more accurate to assess iodine nutrition in pregnancy in $\mu \mathrm{g} / \mathrm{g} \mathrm{Cr}$ units and not $\mu \mathrm{g} / \mathrm{l}$ (as the International Council for the Control of Iodine Deficiency Disorders recommends); however, we report both variants to facilitate comparisons with other studies.

There are several limitations to our study design. The cross-sectional design of the study poses some limitation on the interpretation of the observed associations of gestational age with UIC and $\mathrm{fT}_{4}$. As these are not repeated measurements over the course of pregnancy, but single measurements in different women at different stages of pregnancy, a temporal relationship cannot be confirmed. The use of iodized salt was self-reported; in several cases, the women replied positive when they had actually consumed sea salt, which in reality contains little iodine. In addition, no data are available on the overall iodine status in women of childbearing age in Latvia compared with the iodine status in pregnant women.

\section{Conclusions}

The median UIC indicates iodine deficiency in pregnant women in Latvia. Iodine supplementation $(150 \mu \mathrm{g}$ daily) and regular population-level UIC monitoring among pregnant women and women of reproductive age should be suggested to overcome iodine deficiency and to reach the recommended levels without inducing autoimmune processes.

\section{Acknowledgements}

Financial support: This study was supported by the Latvian Association of Endocrinology and the Latvian National Research Programme BIOMEDICINE. The funders had no role in the design, analysis or writing of this article. Conflict of interest: None. Authorship: I.Ko., D.R., V.P., A.L. and M.D. formulated the research question and designed the study; I.Ka., A.J., E.T., V.V., D.G. and M.M.-K. participated in sample collection and carried out biochemical measurements; I.S. and I.Ko. performed statistical analysis of the data; I.Ko. and M.D. drafted the manuscript; the article text was reviewed and approved by all co-authors. Ethics of buman subject participation: This study was conducted according to the guidelines laid down in the Declaration of Helsinki and all procedures involving human subjects were approved by the P. Stradins Clinical University Hospital Medical Ethics Committee of Latvia. Written informed consent was obtained from all subjects/patients.

\section{References}

1. World Health Organization, UNICEF \& International Council for the Control of Iodine Deficiency Disorders (2007) Assessment of Iodine Deficiency Disorders and Monitoring Their Elimination: Guide for Programme Managers, 3rd ed. Geneva: WHO.

2. Pearce EN, Andersson M \& Zimmermann MB (2013) Global iodine nutrition: where do we stand in 2013? Thyroid 23, 523-528.

3. Gowachirapant S, Winichagoon P, Wyss L et al. (2009) Urinary iodine concentrations indicate iodine deficiency in pregnant Thai women but iodine sufficiency in their schoolaged children. J Nutr 139, 1169-1172.

4. Pessah-Pollack R, Eschler DC, Pozharny Z et al. (2014) Apparent insufficiency of iodine supplementation in pregnancy. J Womens Health (Larchmt) 23, 51-56.

5. Bath SC, Steer CD, Golding J et al. (2013) Effect of inadequate iodine status in UK pregnant women on cognitive outcomes in their children: results from the Avon Longitudinal Study of Parents and Children (ALSPAC). Lancet 382, 331-337.

6. Pop VJ, Kuijpens JL, Van Baar AL et al. (1999) Low maternal free thyroxine concentrations during early pregnancy are associated with impaired psychomotor development in infancy. Clin Endocrinol (Oxf) 50, 147-155.

7. Bougma K, Aboud FE, Harding KB et al. (2013) Iodine and mental development of children 5 years old and under: a systematic review and meta-analysis. Nutrients $\mathbf{5}$, $1384-1416$.

8. Jones G \& Schneider WJ (2006) Intelligence, human capital, and economic growth: a Bayesian Averaging of Classical Estimates (BACE) approach. J Econ Growth 11, 71-93.

9. Bernal J \& Nunez J (1995) Thyroid hormones and brain development. Eur J Endocrinol 133, 390-398.

10. Ausó E, Lavado-Autric R, Cuevas E et al. (2004) A moderate and transient deficiency of maternal thyroid function at the beginning of fetal neocorticogenesis alters neuronal migration. Endocrinology 145, 4037-4047.

11. Berbel P, Guadaño-Ferraz A, Angulo A et al. (1994) Role of thyroid hormones in the maturation of interhemispheric connections in rats. Behav Brain Res 64, 9-14. 
12. Berbel PJ, Escobar del Rey F, Morreale de Escobar G et al. (1985) Effect of hypothyroidism on the size of spines of pyramidal neurons of the cerebral cortex. Brain Res 337, 217-223.

13. Cuevas E, Ausó E, Telefont M et al. (2005) Transient maternal hypothyroxinemia at onset of corticogenesis alters tangential migration of medial ganglionic eminence-derived neurons. Eur J Neurosci 22, 541-551.

14. Morreale de Escobar G, Obregón MJ \& Escobar del Rey F (2000) Is neuropsychological development related to maternal hypothyroidism or to maternal hypothyroxinemia? J Clin Endocrinol Metab 85, 3975-3987.

15. Oppenheimer JH, Schwartz HL, Mariash CN et al. (1987) Advances in our understanding of thyroid hormone action at the cellular level. Endocr Rev 8, 288-308.

16. Solan TD \& Lindow SW (2014) Mercury exposure in pregnancy: a review. J Perinat Med 42, 725-729.

17. Taylor PN, Okosieme OE, Dayan CM et al. (2013) Therapy of endocrine disease: impact of iodine supplementation in mild-to-moderate iodine deficiency: systematic review and meta-analysis. Eur J Endocrinol 170, R1-R15.

18. Teng W, Shan Z, Teng X et al. (2006) Effect of iodine intake on thyroid diseases in China. N Engl J Med 354, 2783-2793.

19. Konrade I, Dambrova M, Makrecka M et al. (2012) Seasonal iodine deficiency in Latvian school children. Thyroid 22, 1088-1089.

20. Dunn JT, Crutchfield HE, Gutekunst R et al. (1993) Two simple methods for measuring iodine in urine. Thyroid $\mathbf{3}$, 119-123.

21. Jaffe M (1886) Ueber die Niederschlag, welchen Pikrinsaure in normalem Harn erzeugt und uber eine neue Reaction des Kreatinins. Z Physiol Chem 10, 391-400.

22. Soldin OP (2002) Controversies in urinary iodine determinations. Clin Biochem 35, 575-579.

23. Stagnaro-Green A, Abalovich M, Alexander E et al. (2011) Guidelines of the American Thyroid Association for the diagnosis and management of thyroid disease during pregnancy and postpartum. Thyroid 21, 1081-1125.

24. Zimmermann MB, Jooste PL \& Pandav CS (2008) Iodinedeficiency disorders. Lancet 372, 1251-1262.

25. Marchioni E, Fumarola A, Calvanese A et al. (2008) Iodine deficiency in pregnant women residing in an area with adequate iodine intake. Nutrition 24, 458-461.

26. Bath SC, Walter A, Taylor A et al. (2014) Iodine deficiency in pregnant women living in the South East of the UK: the influence of diet and nutritional supplements on iodine status. Br J Nutr 111, 1622-1631.

27. Hollowell JG, Staehling NW, Hannon WH et al. (1998) Iodine nutrition in the United States. Trends and public health implications: iodine excretion data from National Health and Nutrition Examination Surveys I and III
(1971-1974 and 1988-1994). J Clin Endocrinol Metab 83, 3401-3408.

28. Moleti M, Di Bella B, Giorgianni G et al. (2011) Maternal thyroid function in different conditions of iodine nutrition in pregnant women exposed to mild-moderate iodine deficiency: an observational study. Clin Endocrinol (Oxf) $\mathbf{7 4}$, 762-768.

29. Becker DV, Braverman LE, Delange F et al. (2006) Iodine supplementation for pregnancy and lactation - United States and Canada: recommendations of the American Thyroid Association. Thyroid 16, 949-951.

30. Arrizabalaga JJ, Larrañaga N, Espada M et al. (2012) Changes in iodine nutrition status in schoolchildren from the Basque Country. Endocrinol Nutr 59, 474-484.

31. Moreno-Reyes R, Carpentier YA, MacOurs P et al. (2011) Seasons but not ethnicity influence urinary iodine concentrations in Belgian adults. Eur J Nutr 50, 285-290.

32. Als C, Haldimann M, Bürgi E et al. (2003) Swiss pilot study of individual seasonal fluctuations of urinary iodine concentration over two years: is age-dependency linked to the major source of dietary iodine? Eur J Clin Nutr 57, 636-646.

33. Samuelsson U, Ludvigsson J, Bottazzo GF et al. (1996) Islet cell surface antibodies are more common in patients and relatives in areas and during seasons with high incidence of insulin-dependent diabetes mellitus. Pediatr Res 40, 695-701.

34. Bozkurt NC, Karbek B, Ucan B et al. (2013) The association between severity of vitamin D deficiency and Hashimoto's thyroiditis. Endocr Pract 19, 479-484.

35. Effraimidis G, Badenhoop K, Tijssen JGP et al. (2012) Vitamin D deficiency is not associated with early stages of thyroid autoimmunity. Eur J Endocrinol 167, 43-48.

36. Guan H, Li C, Li Y et al. (2005) High iodine intake is a risk factor of post-partum thyroiditis: result of a survey from Shenyang, China. J Endocrinol Invest 28, 876-881.

37. World Health Organization (2012) Sodium Intake for Adults and Children. Geneva: WHO.

38. Latrofa F, Fiore E, Rago T \& Antonangeli L (2013) Iodine contributes to thyroid autoimmunity in humans by unmasking a cryptic epitope on thyroglobulin. J Clin Endocrinol Metab 98, E1768-E1774

39. Dosiou C, Barnes J, Schwartz A et al. (2012) Costeffectiveness of universal and risk-based screening for autoimmune thyroid disease in pregnant women. I Clin Endocrinol Metab 97, 1536-1546.

40. Jeyabalan A \& Conrad KP (2007) Renal function during normal pregnancy and preeclampsia. Front Biosci 12, $2425-2437$.

41. Andersen SL, Møller M \& Laurberg P (2014) Iodine concentrations in milk and in urine during breastfeeding are differently affected by maternal fluid intake. Thyroid $\mathbf{2 4}$, $764-772$. 